Please quote as: Leimeister, J. M.; Knebel, U. \& Krcmar, H. (2007): Exploring mobile information systems for chronically ill adolescent patients. Ausgabe/Number: 4, Vol. 3, Erscheinungsjahr/Year: 2007. 


\title{
Exploring mobile information systems for chronically ill adolescent patients
}

\section{Jan Marco Leimeister*, Uta Knebel and Helmut Krcmar}

Technische Universität München

Boltzmannstr.3, 85748 Garching, Germany

E-mail: leimeister@in.tum.de

E-mail: knebel@in.tum.de

E-mail: krcmar@in.tum.de

*Corresponding author

\begin{abstract}
Adolescent cancer patients have to deal with many dependencies and obligations. Very often they are torn out of their social environment and become isolated because of changing therapy cycles and different treatment locations. This causes significant social and economic damage. The objective of this article is to present the first steps of an empirical exploration of the possibilities of mobile IT support for communication and coordination for this target group during treatment and aftercare. Special emphasis is put on the effects of mobile systems on the patient's perceived quality of life. The background we bring to the fore is a four-month field experiment conducted together with the cancer station of the hospital of Heidelberg University. We focus on particularities of and challenges for mobile information systems for patients in Germany and outline necessary future research aspects in this field.
\end{abstract}

Keywords: mobile systems; mobile communication; healthcare; computer-mediated communication; coordination; adolescent cancer patients; mobile IT support.

Reference to this paper should be made as follows: Leimeister, J.M., Knebel, U. and Krcmar, H. (2007) 'Exploring mobile information systems for chronically ill adolescent patients', Int. J. Web Based Communities, Vol. 3, No. 4, pp.404-415.

Biographical notes: Dr. Jan Marco Leimeister is a Senior Researcher and an Assistant Professor at the Information Systems Department, Technische Universität München, Munich, Germany. He runs research groups on virtual communities, e-health and ubiquitous/mobile computing, and manages several publicly funded research projects. Leimeister has worked on different occasions for companies such as DaimlerChrysler, IBM and debis. His teaching and research areas include virtual communities, e-health, IT innovation management, service science, ubiquitous and mobile computing, computer supported cooperative work and information management.

Uta Knebel, Dipl. rer. com., is a full-time Researcher and Scientific Assistant at the Information Systems Department, Technische Universität München, Munich, Germany. She works on projects related to mobile systems and IT-supported product-service bundles for the sports industry. Knebel has worked on different occasions for companies such as IBM, Handelsblatt and Otto Versand. Her research interests include ubiquitious computing, mobile commerce, IT innovation management and adaption/diffusion of innovations. 
Dr. Helmut Krcmar is a Professor of Information Systems and has held the Chair for Information Systems at the Department of Informatics, Technische Universität München (TUM), Germany since 2002. He worked as Post Doctoral Fellow at the IBM Los Angeles Scientific Center, as Assistant Professor of Information Systems at the Leonard Stern School of Business, NYU, and at Baruch College, CUNY. From 1987 to 2002 he was Chair for Information Systems, Hohenheim University, Stuttgart. His research interests include information and knowledge management, IT-enabled value webs, service management, computer supported cooperative work, and information systems in health care and e-government.

\section{Diagnosis of the problem situation}

Cancer diseases are, after cardiovascular diseases, the second most frequent causes of death in Germany. Every year approximately 338000 people are confronted with the diagnosis 'cancer' (Deutsche Krebshilfe, 2003). Out of these, approximately 1800 are children/adolescents under 15 years (Arbeitsgemeinschaft Bevölkerungsbezogener Krebsregister in Deutschland, 2002). Cancer among adolescents is considered a chronic disease (Pfefferbaum, 1990, p.555). It is important that the affected adolescents can have as normal as possible a physical and psychological development since this can be an important step towards a successful coping with the disease (Kyngäs et al., 2000).

The treatment (e.g., in the case of leukaemia) usually lasts two years and consists of several different stages. During the different stages, the patient migrates between locations: permanent hospital phases, ambulant/day hospital phases and home care phases. In some stages of the treatment, cycle patients have to be isolated because the chemotherapy has weakened their immune systems. Extensive medication plans, different physicians, many different consultation appointments and strong side effects very often demand too much from the patient and the family. The adolescent is excluded from important social events in his social network (Rowland, 1990, p.535). Additionally, many patients retreat into their shells because the physical changes in their bodies make them feel fragile and unattractive (Adams-Greenly, 1990, p.563).

These aspects show not only the importance of patient interaction with their existing social networks, but also the relevance of developing new social contacts, for instance with other patients. Additionally, it becomes evident that adolescent cancer patients have to deal with many coordination problems (medical appointments, medication plans, etc.), not to mention control and reminder issues that parents have to deal with. Another challenge emerges from the patients' migrations between contexts/locations (school, hospital, etc.). These insights deliver several starting points for Information and Communication Technology (ICT) support in general and for mobile Information Systems (IS) support in particular.

\section{Developing a mobile information system for adolescent cancer patients}

\subsection{General conditions and requirements for an ICT solution}

Frequently changing locations/contexts determine patients as nomadic users that require ubiquitous access to relevant information and ubiquitous communication possibilities. It is known from innovation research (e.g., Rogers, 1995) that a successful innovation 
(in this case a mobile IS for patients) has to have a relative advantage (subjectively perceived advantage), should be compatible with the values, attitudes and demands of a potential user and its environment, and should be easy to use (comprehensive and manageable), experienceable and observable.

A potentially fruitful approach is a mobile system that follows the user everywhere, or that the user can always carry along. Since mobile phones are widely spread among adolescents, such a system could be based on mobile phones. This would be practical especially given the already existing adaptation of the target group to mobile phone usage.

\subsection{Mobile radiotelephone services and healthcare}

A system based on pulsed radiation (such as GSM/UMTS mobile radiotelephone services) has to deal with some problems in the context of hospitals. In many hospitals and medical practices, the use of mobile phones is restricted or prohibited (Otto and von Mühlendahl, 2003, p.26) because of the potential disturbance to vital medical equipment (Goslich, 2003). However, in reality, this prohibition is often not handled restrictively.

The impact of high-frequency magnetic fields (as caused by mobile phones) on human health is addressed very controversially in academia and practice. Especially new, often inconsistent or contradictory research results cause frequently explosive discussions (Berg et al., 2003). Potential adverse health effects are assigned to thermic effects of radiation, but athermic effects are also suspected. A final evaluation of the biological risks of emissions caused by mobile phones is currently hardly possible (Maes and Haumann, 2002, p.31). The broad usage of cellular phones has existed for only a couple of years; therefore, further research especially on the long-term effects is still necessary before scientifically profound evaluations can be made.

Mobile phones can cause technical disturbances to sensitive medical equipment (e.g., cardiac pacemakers) (Goslich, 2003). Correct shielding against magnetic fields and sufficient distance (radiation loses intensity squared to the distance between sender and receiver) from medical equipment are said to be sufficient for avoiding disturbances (Bundesamt für Strahlenschutz, 2003).

Several types of wireless communication have already entered the healthcare system (Campbell and Durigon, 2003, p.233). Some hospitals already use WLAN, and location-based services (e.g., for emergency calls) and transmission of medical data directly to the clinic bed or from the ambulance to the hospital are currently being explored (Goslich, 2003). In the following we will develop a scenario for mobile IS usage of adolescent cancer patients.

\subsection{A scenario}

Markus Fiedler (fictitious name) was diagnosed with cancer a couple of years ago. The apprentice has recently completed his second therapy cycle. When he is on his way, he always has all his medical data in his pocket: a smartphone which contains all important information about his disease and allows him to maintain contact with his hospital, family and friends. 
Several times a day, the device beeps. Through this sound, the smartphone reminds him to take his medicine. All important data, diagnostic findings (e.g., blood parameters) and a pain/side-effect diary are on his device and are accessible anytime and from any place. Frequently changing schedules and appointments can easily be monitored. Markus' autonomy and independence are increased and mistakes are reduced.

The smartphone allows him to use several communication channels (e-mail, instant messaging, SMS and MMS). Thus he can easily maintain contact with his social network - other patients or schoolmates.

We describe in the following a system that is intended to realise the previously outlined scenario.

\subsection{The applied system}

The hardware chosen for this study is a smartphone, a combination of a PDA, a digital camera and a tri-band mobile phone, distributed by O2 Deutschland GmbH \& Co. OHG (Figure 1).

Figure 1 The applied mobile device XDA II with technical specifications

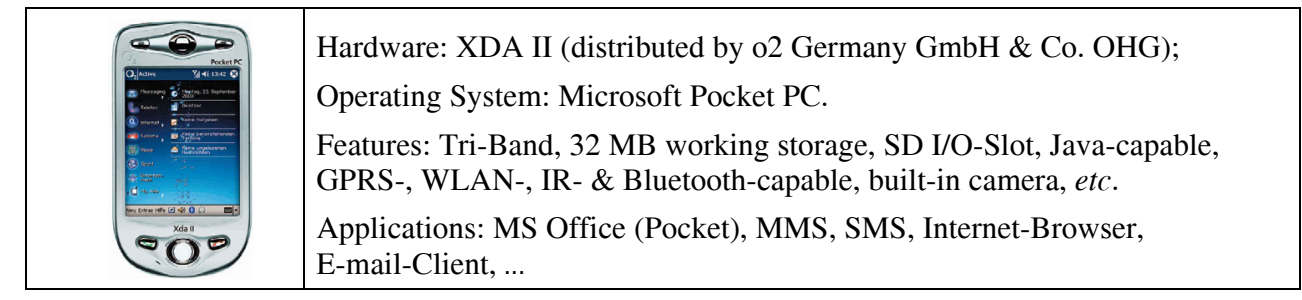

The PDA and camera functionalities can be used separately from the phone unit, allowing usage of the device independently from use as a mobile phone in certain areas. The device can be used as an internet access device, displaying ordinary internet pages with its browser and allowing sending and receiving of e-mail, and, with an extension, it is WLAN compliant. User dialogs can be made via a touch-screen, using either a virtual keyboard or handwriting recognition. There are plenty of applications available for pocket PC devices, most of them being similar to PC desktop applications. For the support of adolescent cancer patients especially, the coordination tools (calendar, diary, notepad) and communication tools (SMS, e-mail, instant messaging) are of major interest and their usage in the field study will be consequently analysed in more detail.

\section{Research design}

The research object, 'mobile information systems for patients', is quite new and hardly investigated. Valid results and insights in this field do not exist yet. Therefore, an explorative research design is applied in the following study in order to grasp deeper insights into this domain. Since general theories about the research object do not yet exist, the research process can hardly start from a theoretical background. Stating and validating hypotheses as common in an empirical-analytical research design cannot be applied here. The intention of this research is the design of reality. According 
to Ulrich (1981, p.S.19), very often the research process starts “... in practice, is focused on analysing the context of use, and ends in practice". This research can be classified in this tradition.

The field study was conducted together with the university hospital in Heidelberg. Based on a four-month prephase with five test users exploring the possibilities of the devices and services without limitation, the actual field study was designed and conducted with 16 patients in a four-month period from February to May 2004. Table 1 shows the allocation of patients along gender and diagnosis.

Table 1 Gender and diagnosis of the participants in the field study

\begin{tabular}{lccc}
\hline & \multicolumn{3}{c}{ Gender } \\
\cline { 2 - 3 } Type of cancer & Male & Female & Overall \\
\hline Leukaemia & 2 & 2 & 4 \\
Bone tumour & 3 & 1 & 4 \\
Lymphoid cancer & 2 & 1 & 3 \\
Other tumour & 2 & 0 & 2 \\
Mucoviscidosis & 0 & 3 & 3 \\
Overall & 9 & 7 & 16 \\
\hline
\end{tabular}

Source: Knebel et al. (2004)

The individual process of using and evaluating technology and innovations depends strongly on the social environment. Also, the resistance of the hospital staff towards the electronic devices had to be overcome. Hence selected hospital staff and selected parents or other relatives were equipped with devices as well. However, they are not included in the following analysis.

\subsection{Introduction of smartphones}

Users will only be able to evaluate the smartphone after a long period of use. This process can be influenced significantly during the introduction phase since basic attitudes are formed then (Döhl, 1983, p.S.200). Consequently, the analysis of the introduction phase is of major importance in this study. In order to explore the potential support and benefit of mobile IS for cancer patients, interventions (i.e., tasks the user had to accomplish in his/her daily context) were designed for supporting self-coordination and communication. For motivating and supporting the use of the devices, additional events were organised, for example support meetings, user meetings and on-the-spot support. The services and applications used in this explorative study were freely available and merely configured for the current requirements; no specially developed software was applied. For a detailed overview of the actions conducted in the introduction phase see Knebel (2004).

\subsection{Interventions: tasks for the users}

The purpose of the interventions/tasks can be assigned to two topic areas: self-coordination and communication support for keeping up the patient's social network. 


\subsubsection{Self-coordination}

During therapy, a patient has to deal with extensive schedules and medication plans that change very often. Also, a close observation of the patient's state of health is crucial. Adolescent patients and their parents are frequently swamped with this necessary monitoring. The use of an XDA in order to coordinate these different tasks can help them keep appointments and supports a well-organised and central data management of all data concerning appointments and medical treatments. Also, parents will be relieved from their duty of continuously reminding their children to make and keep appointments and to take medicine because of the available reminder functionalities. A further result can be the improvement of patient compliance, the reporting of the patient's health status over time.

Services applied in this context were a calendar function for managing appointments and medication plans, a contact list, a task list for daily to-dos and a patient's diary for protocolling pain and health conditions. Introducing the digital management of appointments and the diary was done by giving specific tasks to the test users. They were told to enlist all appointments with doctors, take their medicine and activate the reminder function for these tasks. The handling of the device and its functionalities was explained in detail in a training provided for the users. The users were also provided with printed information.

\subsubsection{Communication support (for maintaining contact to the social network)}

Spending a lot of time in hospitals - often far away from home - and being isolated owing to their health makes it difficult for young people to stay in contact with their peer groups. Building up a new network or community of 'peer sufferers' can help to push the cure process and improve the perceived quality of life (see Section 1). Thus the purpose of using an XDA in this context is to enrich the possibilities of staying in contact with family and friends. The reduction of inhibitions of the patients and their communication partners, as well as the possibility to contact people easily, quickly and irrespective of the location, is also a positive effect caused by the use of the mobile device. Services such as e-mail, MMS, SMS and ICQ were used in this context. The participants were told to explore these communication possibilities and use them for their daily concerns. Restrictions were a cost limit of $100 €$ per device per month. Using the device as a telephone was prohibited particularly to support the use of alternative services. Most participants knew these services from their private mobile phones or home PCs. Creating, sending and receiving SMS and e-mails as well as creating a new e-mail account were also explained in the initial trainings. Additionally, the users received print material with detailed information.

\section{Preliminary empirical results}

Before the devices were handed out to the users, they had to fill out an extensive questionnaire. The existing knowledge of the users plays a major role for 'learning' about new devices and systems (Agarwal and Venkatesh, 2002), therefore the participants were asked about their technical competence and affinity, their PC and mobile phone usage behaviour, and their experiences with managing appointments and medical 
documentation. The functions and applications of the XDA are very similar to those of PCs and mobile phones. An estimation of the existing technical competence was deduced from the stated use of PCs and mobile phones. Fourteen out of the 16 test persons did have a mobile phone, which was used at least once a day by 11 of the persons. All of the users had access to a computer at home. Fourteen used the computer at least once a week, 12 at least once a day. Internet and e-mail were the most frequently used services followed by computer games, applications and chat or ICQ (for detailed results see Knebel et al. (2004)).

In the following, we will focus particularly on the use of the appointment management tools (calendar/reminder functionalities), the patient diary, as well as on the available communication services.

\subsection{Self-coordination}

According to the statements of the patients and the evaluation of the medical staff in the hospital, the self-coordination of the adolescents improved significantly when using the mobile devices. The central data storage and appointment management in one device helped them avoid mistakes and confusion when managing different important appointments. The mobile device led to a more precise compliance with appointments.

Figure 2 Usage of calendar and reminder functionalities $(\mathrm{n}=13)$

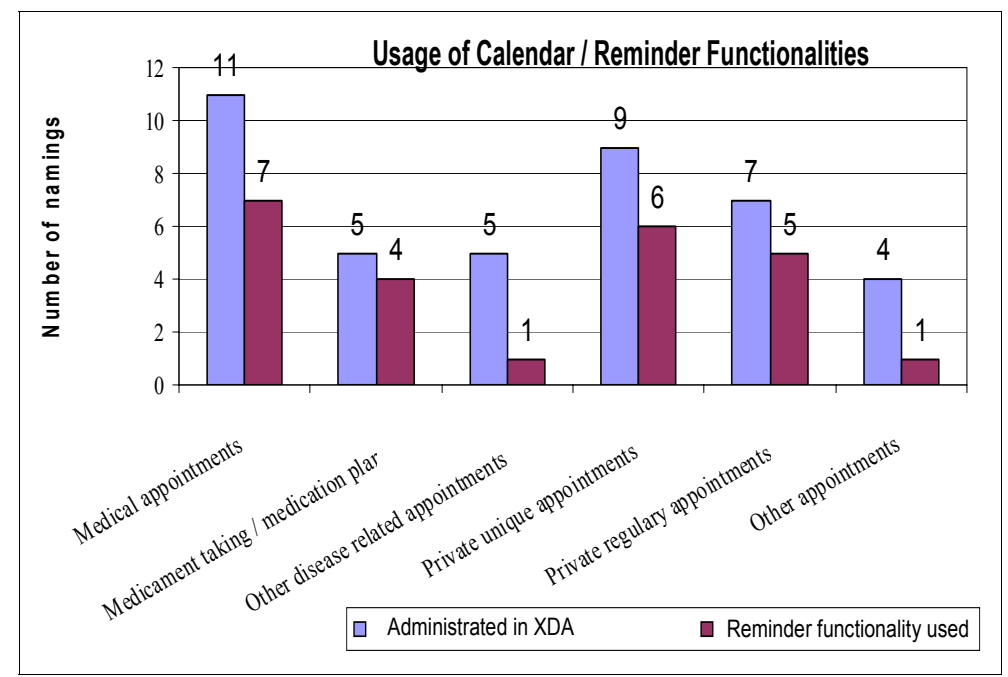

Source: Knebel et al. (2004)

The electronic patient diary was not well accepted among the patients (see Figure 2 in the Appendix). Writing a diary was often seen as of little help and considered laborious. From a medical point of view, using a diary can be a great help during the treatment process when used consequently and continuously. Physicians hope to get more valid insights into cause-effect chains during treatment, data they usually cannot receive since patients are not monitored when they leave the hospital. Thus they expect to gather deeper insights into the compatibility of single and combined therapeutic actions over time. But since there was no immediate benefit for the patients using the diary, they ignored it whenever possible. 
From the empirical exploration of mobile IS for the self coordination of patients, the result can be drawn that mobile services and applications together with mobile devices are appropriate for supporting young people with chronic diseases in managing their self-coordination.

\subsection{Communication support}

The intensity in the use of the communication channel varied a lot among the participants. All in all SMS received the highest relevance in the target group. SMS was used in particular to get in touch spontaneously or to organise ad hoc meetings. In contrast, e-mail was used for transmitting large amounts of content. Instant messaging allowed the most versatile use, e.g., for communicating about the disease or current feelings. However, only a few people communicated over this channel because most of them were not very familiar with it.

Especially encouraging is that computer-mediated communication was very popular among the participants and apparently among young people in general (see Figure 1 in the Appendix). It is also remarkable that anonymity in the communication was not important to the users. It is known from other research that computer-mediated communication lowers barriers (see e.g., Döring, 2003) to talking to other people or to starting a conversation. The communication via chat of the participants of this study focused on friends, while SMS were also sent to family and other patients. Astonishingly, hardly any computer-mediated communication took place between physicians and patients.

Computer-mediated communication is an essential part of the communication structure of young people, more than among other age groups. For keeping and supporting this communication structure even in the case of a severe chronic disease, the access to computer-mediated communication is very important. When desktop PCs were available, the use of a mobile device took a backseat owing to the lesser ease of use. However, in most situations, e.g., in hospitals or rehabilitation centres, desktop PCs were not available. Then a mobile device offered new ways of communication and coordination - the mobile device became an enabler for the patients. Another advantage was that different communication applications and services were integrated in a single device and immediate access was possible.

\subsection{Overall aspects}

The independence of location for usage was considered the most valuable aspect of the mobile information system. Using the device was considered fairly easy, except that the keyboard was often perceived as too small. The device and its services were regarded as an immense help, although they did not make the patients feel better when it came to dealing with the physical aspects of their diseases. The acceptance of the device and its usage among family and hospital staff as well as among the participants was fairly high, and the hospital staff worked as promoters for the field study.

It is difficult to evaluate whether the use of similar mobile IS makes economical sense for patients on the basis of this study. Services such as the appointment management (calendar) and contact management can hardly be valued in a monetary way and compared with the initial and operating costs caused by the system. The initial costs of 
such a system are fixed and relatively high for a private person, while variable costs can be influenced by usage. Costs for internet use can be reduced by using a WLAN card wherever/whenever WLAN access points are available. In this experimental setting, the costs for self-coordination were zero/non existent and the costs for communication support were manageable.

\section{Outlook: chances and challenges of mobile services and devices for patients}

The aspects of self-coordination and communication support for patients seem to bear promising further research potential. Broadening the focus beyond these aspects and the target group opens up the chance to analyse the use of mobile services and devices in the hospital environment in general. The need for further research in this area, however, holds some challenges and limitations. Until now, there are still no reliable and transferable empirical results in this area.

Additionally, these first empirical results from an ongoing research project do not include the effects of specially designed software solutions; in particular, the use of patient diary was suboptimal and did not meet the users' requirements. Further applications could be very valuable for patients and medical staff: online group calendars, resource management or medical information repositories.

Limitations emerge from the prohibition of mobile phone use in some hospitals: they limit the use of such systems in many hospital areas. Additionally, it remains to be seen whether WLAN extensions are capable of overcoming the restrictions mobile phones are facing. Aspects of data security and privacy are of great importance in the context of medical data and hospitals. New applications and services must always meet current legal restrictions, even when some legal aspects in Germany are still 'under construction'.

This research explores the initial potential application areas of mobile IS for patients. Owing to the small number and not representative selection of users and the short period covered in the study, the results have to be understood as a first step towards empirically substantiated research in this area. There is a need for broader verification of the findings as well as for longitudinal studies in order to be able to assess the sustainability of mobile systems for patients and for mobile systems in healthcare.

The exploration of mobile devices for patients is only the first step within a wide field of possible scenarios in health care or hospital sector. The health sector opens many possibilities for improvement of communication, coordination and collaboration of different actors. Other possible scenarios and fields where mobile devices and services could be promising refer to the cooperation of different medical actors, or the cooperation between medical service providers and health insurance.

By the time of the conference, we hope to be able to present further results from the usage of several developed software applications for patient self-documentation and different groupware functionalities, such as automated calendar services with the hospital or individual patient record access. 


\section{Acknowledgements}

The authors would like to express their gratitude to the IIIrd Department of Pediatrics - Department of Pediatric Oncology, Hematology and Immunology (headed by Prof. Kulozik) at the University Children's Hospital Heidelberg, Germany and especially to Mrs. Renate Sedlak, who significantly supported the underlying joint research project between Heidelberg University and Technische Universität München. For further information, please visit http://www.onko-kids.de.

\section{References}

Adams-Greenly, M. (1990) 'Psychosocial interventions in childhood cancer', in J. Holland and J. Rowland (Eds.) Handbook of Psychooncology - Psychological Care of the Patient with Cancer, Oxford, NY: Oxford University Press, pp.562-571.

Agarwal, R. and Venkatesh, V. (2002) 'Assessing a firm's web presence: a heuristic evaluation procedure for the measurement of usability', Information Systems Research, Vol. 13, No. 2, pp.168-186.

Arbeitsgemeinschaft Bevölkerungsbezogener Krebsregister in Deutschland (Eds.) (2002) Krebs in Deutschland - Häufigkeiten und Trends (3. Auflage), Saarbrücken.

Berg, G., Breckenkamp, J. and Blettner, M. (2003) 'Gesundheitliche Auswirkungen hochfrequenter Strahlenexposition', Deutsches Ärzteblatt, Vol. 100, No. 42, pp.A2738-2740.

Bundesamt für Strahlenschutz (2003) 'Biologische und gesundheitliche Wirkungen von hochfrequenten elektromagnetischen Feldern' http://www.bfs.de/elektro/hff/wirkungen.html. (accessed 15 September 2007).

Campbell, R. and Durigon, L. (2003) 'Wireless communication in health care - who will win the right to send data boldly where no data has gone before?', Health Care Manager, Vol. 22, No. 3, pp.233-240.

Deutsche Krebshilfe (2003) 'Krebs: Zahlen, Daten, Fakten', http://www.krebshilfe.de/neu/ medieninfos/zahlen_daten_fakten.htm (accessed 15 September 2007).

Döhl, W. (1983) 'Akzeptanz innovativer Technologien in Büro und Verwaltung - Grundlagen, Analyse und Gestaltung', Innovative Unternehmensführung - Planung, Durchführung und Kontrolle von Innovationen, Vandenhoeck \& Ruprecht, Göttingen.

Döring, N. (2003) 'Sozialpsychologie des Internet: die Bedeutung des Internet für Kommunikationsprozesse, Identitäten, soziale Beziehungen und Gruppen', Auflage, Internet und Psychologie, Hogrefe, Göttingen, Vol. 2.

Goslich, L. (2003) 'Mobilfunk in Kliniken', http://www.klinikheute.de/index.php?l=69\&d $=50698 \& \mathrm{t}=2$, www.klinikheute.de (accessed 15 September 2007)

Knebel, U. (2004) Exploration mobiler Dienste für krebskranke Kinder, Diplomarbeit, Universität Hohenheim.

Knebel, U., Leimeister, J.M. and Krcmar, H. (2004) Empirische Ergebnisse eines Feldversuchs: Mobile Endgeräte für krebskranke Jugendliche - Arbeitspapier, Technische Universität München, Lehrstuhl für Wirtschaftsinformatik, München, No. 4.

Kyngäs, H., et al. (2000) 'Coping with the onset of cancer: coping strategies and resources of young people with cancer', European Journal of Cancer Care, Vol. 10, Nos. 6-11.

Maes, W. and Haumann, T. (2002) 'Mobilfunkstrahlung in Wohngebieten', Wohnung + Gesundheit, No. 105, pp.28-31.

Otto, M. and von Mühlendahl, K.E. (2003) Mobilfunk und Gesundheit - Eine Information für Ärzte. 
Pfefferbaum, B. (1990) 'Common psychiatric disorders in childhood cancer and their management', in J. Holland and J. Rowland (Eds.) Handbook of Psychooncology - Psychological Care of the Patient with Cancer, Oxford, NY: Oxford University Press, pp.544-561.

Rogers, E.M. (1995) 'Diffusion of innovations', Auflage, New York: The Free Press, Vol. 4.

Rowland, J. (1990) 'Developmental stage and adaption: child and adolescent model', in J. Holland and J. Rowland (Eds.) Handbook of Psychooncology - Psychological Care of the Patient with Cancer, Oxford, NY: Oxford University Press, pp.519-543.

Ulrich, H. (1981) 'Die Betriebswirtschaftslehre als anwendungsorientierte Sozialwissenschaft', in M.N. Geist and R. Köhler (Eds.) Die Führung des Betriebes, Festschrift für Curt Sandig, Poeschel Verlag, Stuttgart, pp.S.1-26. 


\section{Appendix}

Figure 1 Importance of communication channel $(n=9)$

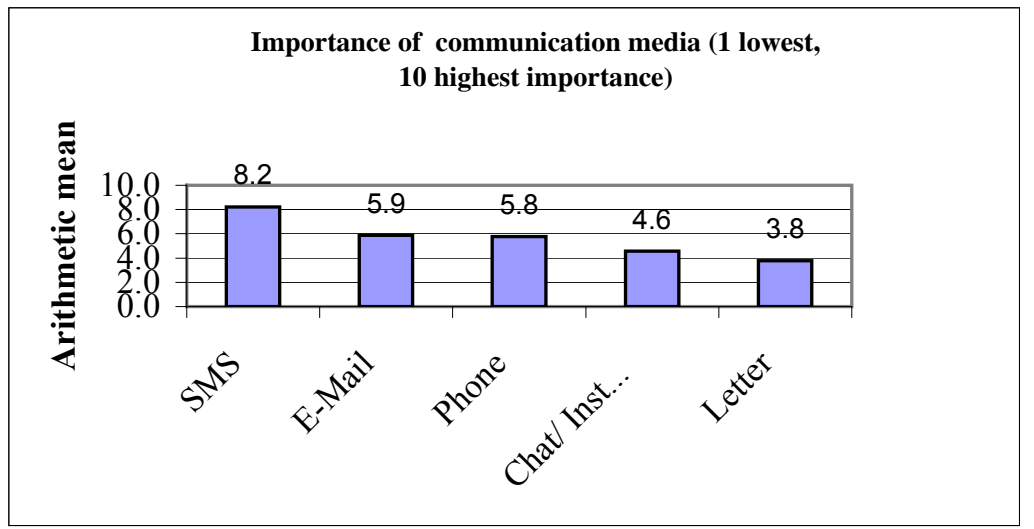

Source: Knebel et al. (2004)

Figure 2 Keeping appointments and perceived benefit of appointment management $(n=13)$
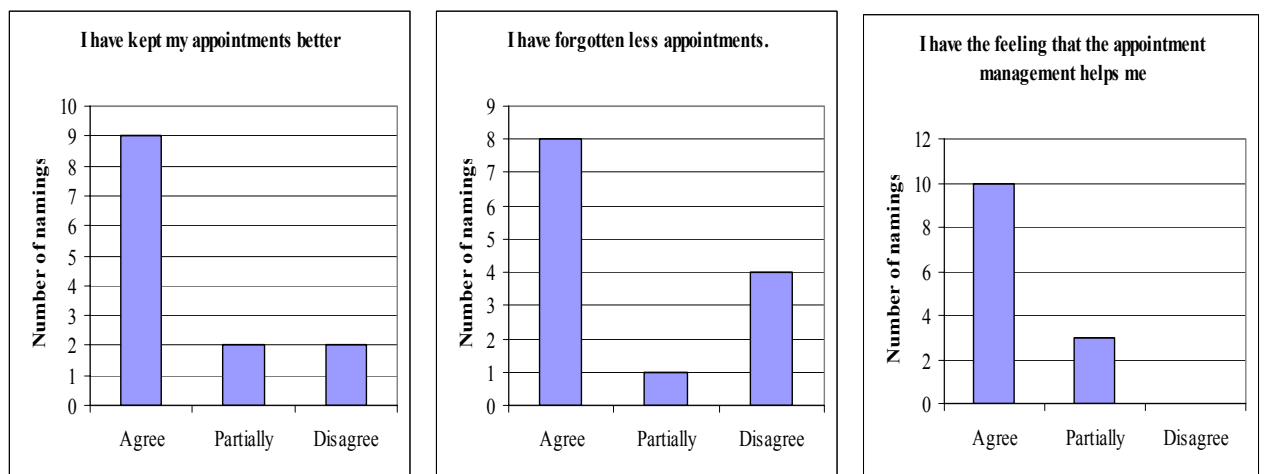

Source: Knebel et al. (2004)

Figure 3 Perceived support of the diary $(n=13)$

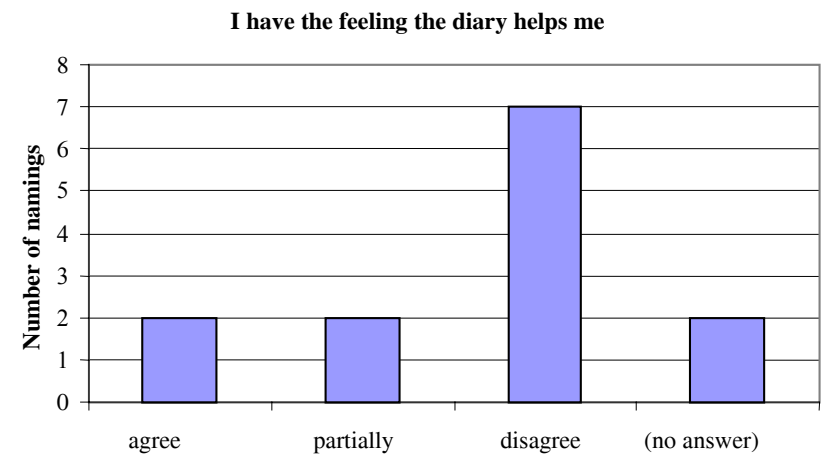

Source: Knebel et al. (2004) 